\title{
Portable Analytical Techniques for Monitoring Volatile Organic Chemicals in Biomanufacturing Processes: Recent Advances and Limitations
}

\author{
Xiaofeng Chen ${ }^{1}$, Runmen Hu ${ }^{1}$, Luoyu Hu ${ }^{1}$, Yingcan Huang ${ }^{1}$, Wenyang Shi ${ }^{1}$, \\ Qingshan $\mathrm{Wei}^{2}$ and Zheng $\mathrm{Li}^{1 *}$ \\ ${ }^{1}$ Institute for Advanced Study, Shenzhen University, Shenzhen, China, ${ }^{2}$ Department of Chemical and Biomolecular \\ Engineering, North Carolina State University, Raleigh, NC, United States
}

OPEN ACCESS

Edited by:

Cosimino Malitesta,

University of Salento, Italy

Reviewed by:

Luca Cappellin,

University of Padua, Italy

Jafar Soleymani,

Tabriz University of Medical

Sciences, Iran

*Correspondence:

Zheng $\mathrm{Li}$

zhengli24@szu.edu.cn

Specialty section:

This article was submitted to

Analytical Chemistry,

a section of the journal

Frontiers in Chemistry

Received: 15 June 2020

Accepted: 10 August 2020

Published: 11 September 2020

Citation:

Chen X, Hu R, Hu L, Huang Y, Shi W,

Wei $Q$ and Li Z (2020) Portable

Analytical Techniques for Monitoring

Volatile Organic Chemicals in

Biomanufacturing Processes: Recent

Advances and Limitations.

Front. Chem. 8:837.

doi: 10.3389/fchem.2020.00837
It is essential to develop effective analytical techniques for accurate and continuous monitoring of various biomanufacturing processes, such as the production of monoclonal antibodies and vaccines, through sensitive and quantitative detection of characteristic aqueous or gaseous metabolites and other analytes in the cell culture media. A comprehensive summary toward the use of mainstream techniques for bioprocess monitoring is critically reviewed here, which illustrates the instrumental and procedural advances and limitations of several major analytical tools in biomanufacturing applications. Despite those drawbacks present in modern detection systems such as mass spectrometry, gas chromatography or chemical/biological sensors, a considerable number of useful solutions and inspirations such as electronic or optoelectronic noses can be offered to greatly overcome the restrictions and facilitate the development of advanced analytical techniques that can target a more diverse range of key nutritious components, products or potential contaminants in different biomanufacturing processes.

Keywords: biomanufacturing, volatile organic chemicals, bioprocess assessments, analytical methods, electronic noses, sensors

\section{INTRODUCTION}

The industry of cell culture manufacturing has grown rapidly over the past decades. With the continuous emergence of state-of-the-art bioprocess technologies, numerous types of biological products, including therapeutic proteins, clinical enzymes, viral or recombinant vaccines, gene therapy vectors, and cells, have been successfully manufactured and put into real-world applications (Carrondo et al., 2012; Pais et al., 2014; Dumont et al., 2016; Lalonde and Durocher, 2017). In principle, conditions required for cell culture cultivation can be optimized and precisely controlled for large-scale industrial production. Nonetheless, cellular metabolism is a complicated process of physical and chemical changes that is subject to various environmental factors (e.g., temperature, $\mathrm{O}_{2}, \mathrm{pH}$ ) (Nielsen and Keasling, 2016). Unexpected disruption in cell behavior due to unknown contaminations could strongly impair quality and reproducibility of bioproducts. Therefore, uncertainty and unpredictability in biopharmaceutical manufacture has posed a great challenge in field monitoring of relevant biological reactions. 
Methods for the measurement of bioprocess variables can be generally divided into two broad groups: on-line and offline measurements (Figure 1A) (Lourenço et al., 2012; Zhao et al., 2015). On-line measurements require the instrument to be present in the line of bioprocess stream to ensure real-time analysis with instant data output, while off-line measurements deal with sample separation from a bioreactor for measurement at a discrete location or time point. Instrumentation selected for on-line or off-line measurements may be invasive that requires the penetration of probes into the fluid medium (e.g., to read $\mathrm{pH}$ and dissolved oxygen), or non-invasive that allows the measurement to be performed without breaking the boundary between the bioprocess stream and the surrounded environment (e.g., headspace gas analysis and aqueous-phase spectroscopic methods).

To date, standard methods for monitoring the status of typical biomanufacturing processes involve the biomolecular quantification using PCR or ELISA techniques (Riahi et al., 2016; Valente et al., 2018; de Bournonville et al., 2019), which is sensitive and specific but dependent on cumbersome analyzing protocols. Other methods based on measuring the content of dissolved oxygen, carbon dioxide or $\mathrm{pH}$ have proven ineffective as they usually predict the occurrence of abnormal states (e.g., contamination) at very late stage of cell cultivation (Bachinger et al., 2002). Moreover, those methods sometimes are not reliable as it could be difficult to observe subtle differences in case an in-line bioreactor control system is used to adjust deviations in oxygen or $\mathrm{pH}$. Other indirect analyses of relevant aqueous or gaseous analytes in a production container, however, involve the complicated and cumbersome incubation of a media sample drawn from the bioreactor. Consequently, the success in early diagnosis of biomanufacturing status is largely dependent on the development of new analytical devices that can perform real-time detection of key metabolites in any cell cultivation process.

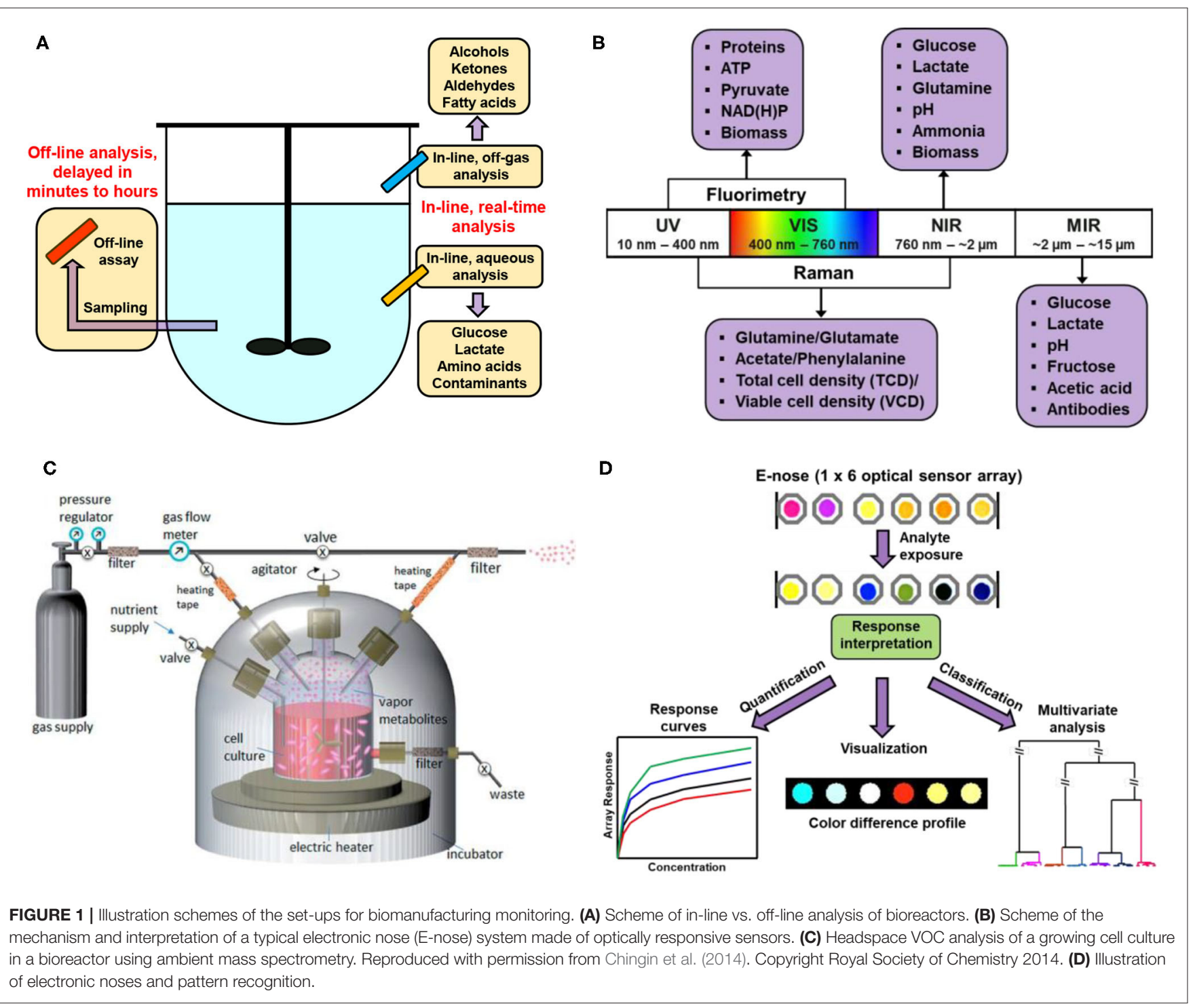


Off-gas analysis is a simple, rapid and non-invasive approach for monitoring cell status during bioproduction. Although such gas detection focuses mainly on oxygen and carbon dioxide, other characteristic volatile compounds are also of great interest to analytical chemists or biologists. It is well-known that the cultivation of a particular cell culture produces a diverse set of volatile organic chemicals (VOCs) as featured metabolites. A wide variety of standard analytical techniques have been applied to the determination of the identities and contents of different gaseous targets, including gas chromatography (GC) (Langejuergen et al., 2015; Lavra et al., 2015; Tang et al., 2017), mass spectrometry (MS) (Schmidberger and Huber, 2013; Chingin et al., 2014; Chippendale et al., 2014; Schmidberger et al., 2014), near-infrared (NIR) spectroscopy (Cimander and Mandenius, 2002; Zhang et al., 2009; Nespeca et al., 2017; Zavala-Ortiz et al., 2020), and multi-wavelength fluorimetry (Faassen and Hitzmann, 2015; Rowland-Jones et al., 2017). Most of those methods, however, suffer from one or more of the drawbacks below: demand on bulk instrumentation, lack of portability, high cost, and long-term sample preparation and analysis. A facile and cost-effective profiling of biological media for precise identification of key components and correlation of the fingerprint to physiological parameters measured by gold standard analytical techniques is highly desirable.

Developing detection methods for continuous and realtime analysis of effluent off-gases has consequently become a pressing demand. The array-based sensors, or "electronic noses" (Hines et al., 1999; Rock et al., 2008; Berna et al., 2009), aim to construct a class of sensor elements with diverse physical and chemical properties for molecular recognition. The first example of an artificial nose was reported by Persaud et al. that mimicked the biological olfactory system using three metal oxides as semiconductor transducers to detect similar biological mixtures (Persaud and Dodd, 1982). This was one of the earliest attempts to use sensor arrays and to successfully distinguish an extensive range of odors. Since then, a similar idea pertaining to array-based sensing technology using an increasing number of analytical devices with cross-reactive sensing elements have emerged that show impressive potentials in sensing applications ranging from environmental monitoring ( $\mathrm{Su}$ et al., 2012; Wei et al., 2014; Jayawardane et al., 2015), to security screening ( $\mathrm{Hu}$ et al., 2014; Bright et al., 2015; Li et al., 2015), to biomedical diagnosis (Konvalina and Haick, 2014; Ulrike and Hossam, 2014; Huang et al., 2015; Tomita et al., 2016), and to food inspection (Maynor et al., 2007; Narsaiah et al., 2012). Innovations in relevant areas are continuing and improvements in sensing technology are constantly needed for resolving limitations of traditional electronic noses that heavily rely on non-specific physical adsorptions of analyte molecules, such as to enhance sensitivity (i.e., limit of detection, or LOD) or selectivity (i.e., limit of recognition, or LOR) of relevant VOCs (Feuz et al., 2010; Li et al., 2019). Array-based optical sensing (i.e., optoelectronic noses) that integrates a diverse range of chemoresponsive and photoactive sensing elements with portable imaging tools proves to be an excellent technique for those goals.

In an attempt to demonstrate the advances and challenges met in the field of bioprocess assessment, we will extensively review the recent development of state-of-the-art techniques for analysis of key components in biomanufacturing process, and mainly focus on optical methods, mass spectrometry, and modern electronic noses. We will cover significant progresses in on-line or off-line monitoring devices and their applications in quality control of typical examples of microbial and mammalian cell cultivation processes, particularly by analyzing the characteristic volatile compounds. Finally, a systematic discussion will be carried out regarding the limitations and future perspectives in bioengineering monitoring technologies.

\section{MAJOR TARGETS IN BIOMANUFACTURING MONITORING}

\section{Aqueous Analytes}

Biomolecules such as glucose, lactate, and amino acid (Schmidt et al., 1998; Roychoudhury et al., 2007; Fan et al., 2016) are important nutrients or metabolites in biomanufacturing. Environmental parameters such as $\mathrm{pH}$, dissolved $\mathrm{O}_{2}$ or $\mathrm{CO}_{2}$ also play pivotal roles on the growth of cell culture media (Meunier et al., 2016; Michl et al., 2019). Monitoring of those major targets during cell culture cultivation is of great value for the regulation and management of biological production. The complexity of the culture medium, however, poses a great challenge to the realtime detection and analysis of target molecules. Especially for offline methods, pretreatment of culture medium such as filtration and isolation could significantly improve the detection sensitivity and specificity. Nevertheless, sampling frequency (once every $12-24 \mathrm{~h}$ ) in off-line contexts is often too low to monitor highly dynamic metabolic processes (Tulsyan et al., 2019), which may result in limited spatiotemporal resolution of the cell metabolic features. Moreover, the pretreatment procedures are usually time-consuming and laborious, and the cultivation fluid is subject to contamination caused by repetitive sampling.

The on-line monitoring methods are expected to resolve those problems mentioned above. Since the detecting units are integrated in the reactor, on-line monitoring methods require no additional steps for sample separation and purification, thus significantly simplifying the analytical procedures and reducing the possibility of sample contamination. In this respect, the non-invasive and contactless spectroscopic techniques are more widely employed in industrial applications. For example, the ultrasound-assisted near-infrared spectroscopy as developed by Kambayashi et al. (2020) used ultrasonic standing waves to generate acoustic radiation force and concentrate the suspended targets at the nodal planes, so that the incoming near-infrared light could precisely quantify target molecules in the colloidal suspension. The measurement error of glucose using this method was as low as $0.6 \%$. In addition, owing to fast data acquisition, high accuracy, and capability of multiparameter analysis, Raman spectroscopy is considered a promising tool in monitoring a wide range of aqueous biological samples (Shaw et al., 1999). For instance, Santos et al. (2018) monitored monoclonal antibody (mAb) cultivations in situ using Raman spectroscopy by adjusting calibration models; an automatic and real-time calibration framework was established by Tulsyan et al. (2019) 
that enabled the integration of traditional Raman models in variable culturing conditions without specific calibration steps, thus increasing the feasibility of Raman techniques in inspecting culture media with highly changeable composition.

Combining with machine-learning techniques (Li et al., 2020), Raman spectroscopy allows for the detection of a large number of analytes or metabolic indices simultaneously, including glucose, glutamate, lactate, metal ions and anions, cell viability and density, which permits multidimensional data analysis for comprehensive profiling of the biological signatures (Henriques et al., 2009). Other optical measurements in bioengineering involve UV/Vis (Noui et al., 2002), mid-infrared or fluorescence spectroscopy (Figure 1B); electrical approaches include terahertz spectroscopy (Plusquellic et al., 2007) and electrochemical sensors (Joo and Brown, 2008). Each technique has its own advantages and limitations that call for further optimization in detection mechanism and instrumentation.

\section{Volatile Organic Chemicals}

Carbon dioxide and oxygen are most commonly targeted volatiles in the off-gas stream, and studies of $\mathrm{CO}_{2}$ or $\mathrm{O}_{2}$ monitoring using infrared (Cimander and Mandenius, 2002) or paramagnetic (Parente et al., 2004) spectrometry have been well-established. In addition to regular gas emissions from a general bioprocess, there are a wide variety of VOCs with distinctive chemical functionalities for targeting. For example, ethanol, methanol, and isoprenoids are abundantly present in various microbial production processes, and are among the most commonly measured metabolic species in bioproduction (Wang et al., 2020).

Unlike microbial species, mammalian cells can feed on lipids and produce accordingly different classes of metabolites that are rarely found in the culture of microorganisms (FernándezGarcía et al., 2020). Those products typically consists of ketones, long-chain (> C5) alcohols, alkanes or alkenes, esters, etc. The unique composition of emitted VOCs can be utilized for discrimination of different mammalian cell lines, and examined by an extensive selection of analytical methods, including gas chromatography (Filipiak et al., 2010), optical spectroscopy, mass spectroscopy (MS) (Biasioli et al., 2011), and electronic noses (E-noses) comprising an array of metal oxide or conductive polymer sensors. Recently, proton transfer reaction - mass spectroscopy (PTR-MS) (Brunner et al., 2010) has shown great potential in the detection of VOCs during fed-batch cultivation of recombinant CHO cell cultures (Schmidberger et al., 2014). By applying a soft ionization technology, this technique can avoid producing excessive molecular fragments and therefore simplify spectral interpretation. The method is able to identify eight most abundant VOCs in the bioreactor off-gases, including small molecules such as methanol, acetaldehyde, as well as some long-chain organic species such as 3- or 4-methyl-2-pentanone, hexanoic acid, or C6 ester. The study demonstrates the great advantage of PTR-MS technology in off-gas monitoring of cultivated cell cultures over electronic noses in terms of chemical specificity, and over gas chromatographic methods in terms of data accuracy and discriminatory efficiency.

\section{ANALYTICAL METHODS}

Modern techniques in bioengineering are urgently needed for a total bioprocess assessment, aiming significant transitions from batch to on-line and instantaneous monitoring (Teixeira et al., 2009; Roch and Mandenius, 2016; Holzberg et al., 2018). Conventional techniques constantly used for bioprocess monitoring are well-established yet relatively outdated (e.g., the classical Clark electrodes), thus demanding the invention of novel and easy-to-use devices. In this context, the utilization of analytical methods is expanding rapidly from laborious PCR/ELISA methods or chromatographic/spectroscopic systems to recently developed electronic noses/tongues using electrochemical, optical or other solid-state sensors. In this section, we will summarize several most common approaches for biomanufacturing analysis.

\section{Gas Chromatography (GC)}

$\mathrm{GC}$ is one of the most popular and active analytical technologies in bioengineering (Mcnair and Miller, 2010). The analytes of interest could be in gas, liquid or solid, with molecular weight ranging from 2 to $1,000 \mathrm{Da}$, which has shown extensive applications in food inspection (Bianchi et al., 2006), pesticide detection (Zhang et al., 2006), environmental monitoring (Viola et al., 2019), forensic investigation (Alexandrino et al., 2019), and quality control of petroleum products (Coutinho et al., 2018). In addition, GC analysis is widely used in the inspection of human organ functions (Young et al., 2019) and screening of cancer cells, such as hematological malignancies (Tang et al., 2017) and breast cancer (Lavra et al., 2015). GC is also considered the gold standard technique for biomanufacturing monitoring. For example, McConnell and Antoniewicz (2016) exploited GC with MS detector (GC-MS) to measure the carbohydrate composition in the culture medium of chlorella vulgaris. Compared to former methods for carbohydrate analysis, GC is advantageous in data reproducibility, accuracy, and the capability of multiplexed detection. Recently developed two-dimensional GC-MS benefits from two-step separation (apolar vs. polar) that greatly improves the spatiotemporal resolution of GC (Yu et al., 2017). However, particularly for off-line analysis, sample collection and pretreatment would complicate the analyzing procedures, and even bring in unexpected contamination. As an indirect but effective method, headspace sampling is a field-deployable method that can integrate the GC system directly into the bioreactor, so as to skip the sampling step, speed up analyzing rate, and reduce the possibility of sample contamination. The concept of monitoring characteristic VOCs have been successfully demonstrated in the identification of microalgae (Guidetti Vendruscolo et al., 2019) and pathogenic bacteria (Chen et al., 2017). With the continuous progress on new columns (packed or capillary), separation mechanisms, and expansion of molecular data library, it is expected to further improve GC detection sensitivity and resolution of relevant species regarding particular applications in bioengineering, such as proteomics/lipidomics. 


\section{Mass Spectrometry (MS)}

The rapid development of MS since the past few decades have dramatically expanded the fields research to many aspects in bioengineering, such as cellular proteomics or metabolomics (Ali et al., 2018; MacMullan et al., 2019; Li and Shui, 2020); in particular, the invention of matrix assisted laser desorption ionization (MALDI)-MS (Hillenkamp et al., 1991) pave the path for rapid and simple fingerprinting of biomacromolecules (Kawano et al., 2019). Advances in recent years have led to a variety of novel ionization methods or detection mechanisms for biomanufacturing assessment. As a typical example, GCMS tandem technique is considered the gold standard for

TABLE 1 | List of techniques of mass spectrometry or electronic noses employed for off-gas monitoring of specific cell cultivation.

\begin{tabular}{|c|c|c|c|c|}
\hline Cell culture & Bioprocess monitored & Mass spectrometry & Volatiles detected & References \\
\hline \multicolumn{5}{|l|}{ MASS SPECTROMETRY } \\
\hline Escherichia coli JM 109 & $\begin{array}{l}\text { Accidental infection by } \\
\text { comamonas testosteroni }\end{array}$ & Time-resolved SIFT-MS & $\begin{array}{l}\text { Ethanol, acetaldehyde, hydrogen sulfide } \\
\text { and ammonia }\end{array}$ & $\begin{array}{l}\text { Chippendale et al., } \\
2011\end{array}$ \\
\hline JEKO and SHI-1 cell lines & Tissue culture & SPME-GC-MS & $\begin{array}{l}\text { Dimethyl sulfide, 2,4-dimethylheptane, } \\
\text { methylbenzene, o-xylene, dodecane, } \\
\text { 1,3-di-tert-butylbenzene, ethanol, hexanal, } \\
\text { and benzaldehyde }\end{array}$ & Tang et al., 2017 \\
\hline $\begin{array}{l}\text { Streptococcus } \\
\text { thermophilus, and } \\
\text { bulgaricus }\end{array}$ & $\begin{array}{l}\text { Lactic acid fermentation } \\
\text { of milk }\end{array}$ & PTR-TOF-MS & $\begin{array}{l}\text { Acetaldehyde, 2-propanone, diacetyl, } \\
\text { acetoin, etc. }\end{array}$ & Soukoulis et al., 2010 \\
\hline $\begin{array}{l}\text { A549 epithelial cell line, and } \\
\text { Pseudomonas aeruginosa }\end{array}$ & $\begin{array}{l}\text { Co-culture of lung } \\
\text { epithelial cell line with } \\
\text { Pseudomonas } \\
\text { aeruginosa }\end{array}$ & $\begin{array}{l}\text { thermal } \\
\text { desorption-GC-MS }\end{array}$ & $\begin{array}{l}\text { 3-methyl-1-butanol, acetone, ethylidene } \\
\text { cyclopropane, ethanol, tert-butyl ethyl } \\
\text { ether, methyl tert butyl ether, etc. }\end{array}$ & Lawal et al., 2018 \\
\hline $\begin{array}{l}\text { Lactobacillus fermentum } \\
\text { IMD0130101 }\end{array}$ & $\begin{array}{l}\text { Submerged } \\
\text { fermentations }\end{array}$ & SIFT-MS & Ethanol & $\begin{array}{l}\text { Van Kerrebroeck et al., } \\
2015\end{array}$ \\
\hline Lactobacillus pentosus & Milk fermentation & SPME-GC-MS & $\begin{array}{l}\text { Twenty-four kinds of VOCs including } \\
\text { acetaldehyde, acetone, etc. }\end{array}$ & Pan et al., 2014 \\
\hline Nodulisporium TI-13 & Beet pulp fermentation & PTR-MS & $\begin{array}{l}\text { Ethanol, methanol, acetaldehyde, } \\
\text { terpenes, and terpenoids }\end{array}$ & Schoen et al., 2016 \\
\hline $\begin{array}{l}\text { Escherichia coli } \\
\text { HMS174(DE3) }\end{array}$ & $\begin{array}{l}\text { Escherichia coli } \\
\text { cultivation }\end{array}$ & PTR-MS & Total VOCs & Luchner et al., 2012 \\
\hline S. cerevisiae & Mead fermentation & PTR-MS & Total VOCs & Cuenca et al., 2016 \\
\hline $\begin{array}{l}\text { Eleven lactic acid bacteria } \\
\text { including } E \text {. casselliflavus } \\
\text { FMAC163, et al. }\end{array}$ & $\begin{array}{l}\text { Caciocavallo Palermitano } \\
\text { cheese fermentation }\end{array}$ & SPME-GC-MS & $\begin{array}{l}\text { Alcohol, aldehydes, ketones, esters, } \\
\text { aromatic, organic acid, hydrocarbons, etc. }\end{array}$ & Guarrasi et al., 2017 \\
\hline Cell culture & Bioprocess monitored & E-nose type & Volatiles detected & References \\
\hline \multicolumn{5}{|l|}{ E-NOSE } \\
\hline Recombinant $\mathrm{CHO}$ & $\begin{array}{l}\text { Early detection of } \\
\text { bacterial infection }\end{array}$ & 10 MOSFET, 12 MOS & $\mathrm{O}_{2}$ & Bachinger et al., 2002 \\
\hline $\begin{array}{l}\text { Saccharomyces cerevisiae } \\
\text { (a yeast) }\end{array}$ & $\begin{array}{l}\text { Non-volatile metabolites } \\
\text { during fermentation }\end{array}$ & $18 \mathrm{MOS}$ & Ethanol, acetic acid, and acetaldehyde & $\begin{array}{l}\text { Liden et al., 2000; } \\
\text { Calderon-Santoyo } \\
\text { et al., } 2010\end{array}$ \\
\hline $\begin{array}{l}\text { Recombinant Escherichia } \\
\text { coli }\end{array}$ & Metabolic burden & 19 MOSFET, 10 MOS & Biomass and other non-specific gases & Bachinger et al., 2001 \\
\hline $\begin{array}{l}\mathrm{CHO} \text { and } \mathrm{Sf}-9 \text { insect cell } \\
\text { culture }\end{array}$ & $\begin{array}{l}\text { Microbial and viral } \\
\text { contaminants }\end{array}$ & 10 MOSFET, 6 MOS & $\begin{array}{l}\text { Acetic acid, ammonia, acetone, and } \\
\text { ethanol }\end{array}$ & Kreij et al., 2005 \\
\hline $\begin{array}{l}\text { Morinda citrifolia and } \\
\text { Nicotiana tabacum (plant } \\
\text { cells) }\end{array}$ & $\begin{array}{l}\text { Biomass and metabolite } \\
\text { concentration }\end{array}$ & $\begin{array}{l}19 \mathrm{MOS} \text { and } \mathrm{a} \mathrm{CO}_{2} \\
\text { sensor }\end{array}$ & Biomass and other non-specific gases & Komaraiah et al., 2004 \\
\hline Bacillus subtilis & Sporulation events & 10 MOSFET, 6 MOS & Volatiles from spores & Clemente et al., 2008 \\
\hline $\begin{array}{l}\text { Lactobacillus fermentum } \\
\text { Ogi E1 }\end{array}$ & Lactic fermentation & $18 \mathrm{MOS}$ & Ethanol & $\begin{array}{l}\text { Calderon-Santoyo } \\
\text { et al., } 2013\end{array}$ \\
\hline Recombinant $\mathrm{CHO}$ & Cellular state transitions & 10 MOSFET, 6 MOS & Biomass and other non-specific gases & Bachinger et al., 2000 \\
\hline Acidithiobacillus thiooxidans & $\begin{array}{l}\text { Maturation of air-lift } \\
\text { bioreactors }\end{array}$ & $11 \mathrm{MOS}$ & $\begin{array}{l}\text { Alcohols, hydrocarbons, sulfur } \\
\text { compounds, etc. }\end{array}$ & Rosi et al., 2012 \\
\hline
\end{tabular}

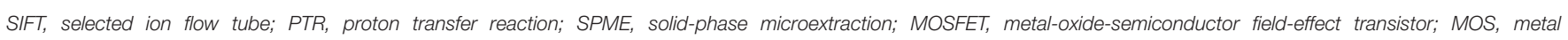
oxide semiconductor. 
general VOC analyses (Romano et al., 2015). The recently developed direct injection (i.e., ambient) mass spectrometry (DI-MS) requires no complicated steps for sample separation or purification; gaseous analytes from the headspace could be introduced directly into the mass spectrometry system, thus significantly facilitating the sample analysis procedures (Figure 1C). Among various DI-MS techniques, proton transfer reaction-MS (PTR-MS) (Hansel et al., 1995) and selected ion flow tube-MS (SIFT-MS) (La Nasa et al., 2019) represent the cutting-edge technologies, which takes advantages of relatively simple instrumentation and controllable ionization conditions. Combining with time-of-flight (TOF) mass analyzer, the detection sensitivity could reach parts per trillion by volume (pptv) level, with $\mathrm{m} / \Delta \mathrm{m}$ up to 15,000 (Soukoulis et al., 2010). Examples of MS techniques for bioproduction analysis were listed in Table 1.

\section{Electronic Nose}

The advent of electronic nose (E-nose) has provided alternative tools for sensing VOCs in the bioreactors. E-noses employed for this purpose generally consist of an array of responsive gas sensors, each of which allows for the determination of both the identity and concentration of unknown gas analytes. The unique pattern representing the overall sensor response caused by the exposure of VOCs can be used as a "fingerprint" for the identification of cell cultures of microorganisms or mammalian cell lines (Figure 1D). Pattern recognition based on a dozen of sensor elements, in a sense, is more accurate than the identification made by only one or two sensors. The distinctions among different cell cultures can be demonstrated by a diverse range of clustering and classification methods. Clustering methods seek to describe a dataset into groups, or clusters; classification methods attempt to predict information about an unknown sample based on previously acquired data. Common statistical methods for biomanufacturing monitoring include: principal component analysis (PCA) (Albrecht et al., 2018; Chen et al., 2020) linear discriminant analysis (LDA) (Wang et al., 2012; Silva et al., 2017), partial least square (PLS) regression/discrimination analysis (Kammies et al., 2016; Matthews et al., 2016; McCartney et al., 2019; Pontius et al., 2020; Zavala-Ortiz et al., 2020), and artificial neural network (ANN) (López et al., 2017; Oyetunde et al., 2018).

Most e-noses for volatile gas measurement generally rely on the adsorption of gas molecules to the surface of sensors. The sensing instrumentation usually consists of an array of sensors that have different binding capabilities to gaseous analytes and output electrical signals (e.g., changes in current, voltage or resistance) as a result of the selective adsorption. Common Enoses include conductive polymers (Kiilerich-Pedersen et al., 2011), metal oxide semiconductors (MOS) (Liden et al., 2000; Calderon-Santoyo et al., 2010), metal oxide semiconductor field effect transistors (MOSFET) (Bachinger et al., 2001; Komaraiah et al., 2004; Kreij et al., 2005; Clemente et al., 2008), quartz crystal microbalances (QCM) (Shen et al., 2007), surface acoustic wave (SAW) devices (Rocha-Gaso et al., 2009), and chemiresistive or amperometric sensors (Chiu and Tang, 2013; Ahmed et al., 2014). Compared to single sensing, the highly integrated, multiplexing sensor array satisfies the requirements for both identification and quantification of targeted VOCs.

Due to the ease of sensor fabrication and deployment, Enoses have found extensive applications in the analysis of off-gas emissions from the bioproduction of a large number of microorganisms, mammalian or insect cell lines (Namdev et al., 1998; Bachinger and Mandenius, 2000; Mandenius, 2000; Cimander et al., 2002). An early study was report by Liden et al. (2000) to quantify major metabolites during fermentation of a yeast, Saccharomyces cerevisiae, through on-line analysis of the off-gas emission using a set of 10 MOSFETs (e.g., ethanol, acetaldehyde, etc.). Other successful applications of Enoses in detecting mammalian cell lines have been continuously reported (Calderon-Santoyo et al., 2010; Cuypers and Lieberzeit, 2018). Examples involve the monitoring of metabolic burden in the fermentation process of a recombinant Escherichia coli (Bachinger et al., 2001), the early detection of bacterial/fungal contaminations in mammalian (e.g., recombinant $\mathrm{CHO}$ cells) and in insect (e.g., recombinant Sf-9 cell for protein production) cell lines (Bachinger et al., 2002; Kreij et al., 2005), as well as the quantification of plant cell cultures (e.g., Morinda citrifolia and Nicotiana tabacum) (Komaraiah et al., 2004), and of spore concentration in the cultures of Bacillus subtilis, a species for oral bacteriotherapy of gastrointestinal diseases (Clemente et al., 2008). Different E-noses employed for microbial and mammalian cell detection with various purposes were listed in Table $\mathbf{1 .}$

\section{Optoelectronic Nose}

The thriving development of novel techniques in chemical sensing (Albert et al., 2000; Nakamoto and Ishida, 2008; Wu et al., 2015) has led to the availability of a more integrative type of sensory tools as alternatives to traditional electronic noses, namely the "optoelectronic nose" (OE-nose) (Rakow and Suslick, 2000). OE-nose is a class of optical sensor arrays based on chemoresponsive colorants to probe chromogenic or fluorimetric changes induced by specific interactions. This provides a high dimensionality to chemical sensing that permits high sensitivity (often down to ppb or even ppt levels), impressive discrimination among very similar odorants and superb fingerprinting of extremely similar mixtures over a wide range of categories, both in gaseous and liquid phases. Optical sensor arrays therefore sufficiently overcome the limitations of traditional array based sensors that solely depend on physical adsorption or non-specific chemical interactions.

Optical array sensing has shown excellent performance in the detection and identification of diverse analytes, ranging from chemical hazards (Li and Suslick, 2019) to medical biomarkers (Wang et al., 2016; Li and Suslick, 2018), and to food additives (Schaude et al., 2017). Likewise, this method can be promisingly applied to the analysis of effluent VOCs from the cultures accumulated in the headspace of bioreactors, as a way of monitoring microbial or cellular activities. Suslick et al. have designed colorimetric sensor arrays coupled to optoelectronic readers for the identification of different bacteria and fungi based on the off-gas analysis (Carey et al., 2011; Li et al., 2019). The concept of such detector is to incorporate chemoresponsive colorants in an array of sensors, which 
undergoes significant colorimetric or fluorimetric changes in response to VOCs through an extensive range of chemical interactions including bond formation or ligand coordination, proton acid-base interactions, hydrogen or halogen bonding, charge-transfer and $\pi-\pi$ stacking, etc. The array is digitally imaged before and during exposure, and an optical difference profile is generated in real time by subtracting the beforeexposure image from images after gas exposure. Simple pattern recognition techniques give essentially error-free recognition of gas analytes based on a numerical library ( $3 \mathrm{~N}$ vectors of redgreen-blue (RGB) difference changes). Such libraries require very little memory and are easily updatable and transferrable, thus enabling the instant and continuous monitoring of biological production.

\section{DISCUSSION}

Biomanufacturing industry has received remarkable improvements in process efficiency and productivity over the past decade. Efforts for bioprocess inspection are placed on enhancing process robustness and product quality using a wide range of in-situ analytical techniques. For effective bioprocess monitoring, it is critical to characterize physiological states and measure main process variables, such as key nutrients and metabolites in the aqueous phase, or off-gas effluents as characteristic VOCs. Numerous chromatographic and spectroscopic techniques, particularly gas chromatography and mass spectrometry, have shown impressive potentials in real-time profiling of the cell culture status. Meanwhile, the optimization of chemometric models that provide quantitative and predictable correlation between the spectra pattern and targeted key metabolites is also of great importance. Much of the endeavors have been focused on classical analytical instrumentation and off-line measurements, while little has been related to in-situ monitoring protocols.

Admitted, a complete quantitative component-by-component analysis using an effective analytical method is always desirable. Nevertheless, one seldom really wants to know clearly the identities of hundreds of compounds present in a complex mixture, such as the chemical composition of a biomanufacturing media. Alternatively, those goals are better fulfilled by a highly discriminant fingerprinting of the entire mixture. Such fingerprinting strategies permit comparison to standards, identification of chemical class or origin of the species, and correlation of the fingerprint to properties determined by other standard techniques. In the case where component-by-component analysis is required, the tandem approach that combine a separation technique (e.g., various chromatographic approaches or electrophoresis) with an analysis technique is typically employed. Sensor array techniques such as electronic or optoelectronic noses are most commonly used for direct fingerprinting of complex mixtures without sophisticated instrumental operation and complicated sample separation.

Due to miniaturized and multiplexed features, E-noses have received tremendous attention in recent years in connection with a broad range of bioengineering fields. E-nose devices are constructed from an array of engineered sensors that provide a pattern of electronic signals in response to a given analyte; therefore, they are distinctive from other techniques for biochemical analysis in that they are primarily designed to recognize gas mixtures as a whole without the need for identifying individual chemical species in the mixture. For this reason, E-noses are not intended for determining the chemical composition of a complex gas mixture, but rather are most useful for identifying the produced "chemical bouquet." Even for highly close gas mixtures from very similar species, it is possible to tell their subtle differences using effective E-noses.

Despite the great success achieved by E-noses in monitoring cellular physiology, traditional E-noses often suffer from low chemical specificity and sensitivity due to simple or non-specific interactions with the biomarkers (i.e., physical adsorption). The other shortcoming lies in the sensor drift, which leads to poor stability and reproducibility in sensor outputs. Moreover, Enoses could be easily interfered by ambient humidity or pressure changes, which demand repetitive calibration of the sensor devices. In addition, some E-noses have to be operated under restricted conditions. For example, metal oxide semiconductors are generally required to work at high temperatures (generally over $100^{\circ} \mathrm{C}$ ) with a large amount of power consumption. Therefore, there remains an urgent demand for improving sensing performance of the current electronic sensors.

Array-based optical sensing, on the other hand, attempts to probe mostly the chemical reactivity of analytes rather than their physical properties. That provides a high dimensionality for biosensing purposes and enables high sensitivity (often down to ppb levels) and remarkable discrimination among highly similar targets in gaseous phases. The optoelectronic noses made of chromogenic or fluorometric elements therefore overcome the limitations of traditional electronic sensors that solely depend on physisorption or non-specific chemical interactions. Such concept of optical array sensing has shown excellent performance in the detection and identification of a diverse set of analytes, ranging from industrial toxins to energetic explosives, to human biomarkers, and of course, to products of great relevance to biomanufacturing processes.

In conclusion, instead of the conventional and stepwise offline sample analyses that have to be conducted in laboratory settings, developing non-destructive optical sensing techniques for real-time monitoring of effluent gases in large-scale bioreactors is highly desirable. Although there is very limited number of research reported on the use of optical array sensing for profiling featured headspace volatiles from a typical bioproduction process, we expect that an increasing number of optical sensor array are likely to be developed for this particular application, and more advanced strategies along with a significantly thriving market in this area are likely to be established in the near future.

\section{AUTHOR CONTRIBUTIONS}

$\mathrm{XC}$ and $\mathrm{ZL}$ took the lead in writing the manuscript. All authors provided critical feedback, helped shape the manuscript, and references. 


\section{FUNDING}

This work was supported by the Initial Scientific Research Fund of Young Teachers in Shenzhen University (No. 000002110553), Guangdong Joint Fund of Fundamental and Applied Research
(No. 2019A1515110242), and Guangdong University Young Talents Project (No. 2019KQNCX127). QW acknowledges funding support from the National Institute for Innovation in Manufacturing Biopharmaceuticals (NIIMBL) (Award \# PC2.2-106).

\section{REFERENCES}

Ahmed, A., Rushworth, J. V., Hirst, N. A., and Millner, P. A. (2014). Biosensors for whole-cell bacterial detection. Clin. Microbiol. Rev. 27, 631-646. doi: 10.1128/CMR.00120-13

Albert, K. J., Lewis, N. S., Schauer, C. L., Sotzing, G. A., Stitzel, S. E., Vaid, T. P., et al. (2000). Cross-reactive chemical sensor arrays. Chem. Rev. 100, 2595-2626. doi: $10.1021 / \mathrm{cr} 980102 \mathrm{w}$

Albrecht, S., Kaisermayer, C., Gallagher, C., Farrell, A., Lindeberg, A., and Bones, J. (2018). Proteomics in biomanufacturing control: protein dynamics of $\mathrm{CHO}-\mathrm{K} 1$ cells and conditioned media during apoptosis and necrosis. Biotechnol. Bioeng. 115, 1509-1520. doi: 10.1002/bit.26563

Alexandrino, G. L., Tomasi, G., Kienhuis, P. G. M., Augusto, F., and Christensen, J. H. (2019). Forensic investigations of diesel oil spills in the environment using comprehensive two-dimensional gas chromatography-high resolution mass spectrometry and chemometrics: new perspectives in the absence of recalcitrant biomarkers. Environ. Sci. Technol. 53, 550-559. doi: 10.1021/acs.est.8b05238

Ali, A. S., Raju, R., Ray, S., Kshirsagar, R., Gilbert, A., Zang, L., et al. (2018). Lipidomics of CHO cell bioprocessing: relation to cell growth and specific productivity of a monoclonal antibody. Biotechnol. J. 13:1700745. doi: 10.1002/biot.201700745

Bachinger, T., and Mandenius, C.-F. (2000). Searching for process information in the aroma of cell cultures. Trends Biotechnol. 18, 494-500. doi: 10.1016/S0167-7799(00)01512-2

Bachinger, T., Mandenius, C.-F., Striedner, G., Clementschitsch, F., Dürrschmid, E., Cserjan-Puschmann, M., et al. (2001). Non-invasive detection of the metabolic burden on recombinant microorganisms during fermentation processes. J. Chem. Technol. Biotechnol. 76, 885-889. doi: 10.1002/jc tb. 463

Bachinger, T., Riese, U., Eriksson, R., and Mandenius, C.-F. (2000). Monitoring cellular state transitions in a production-scale $\mathrm{CHO}$-cell process using an electronic nose. J. Biotechnol. 76, 61-71. doi: 10.1016/S0168-1656(99)00179-0

Bachinger, T., Riese, U., Eriksson, R. K., and Mandenius, C.-F. (2002). Gas sensor arrays for early detection of infection in mammalian cell culture. Biosens. Bioelectron. 17, 395-403. doi: 10.1016/S0956-5663(01)00315-3

Berna, A. Z., Anderson, A. R., and Trowell, S. C. (2009). Bio-benchmarking of electronic nose sensors. PLoS ONE 4:e6406. doi: 10.1371/journal.pone.0006406

Bianchi, F., Careri, M., Mangia, A., and Musci, M. (2006). Development and validation of a solid phase micro-extraction-gas chromatography-mass spectrometry method for the determination of furan in baby-food. J. Chromatogr. A 1102, 268-272. doi: 10.1016/j.chroma.2005.10.056

Biasioli, F., Yeretzian, C., Märk, T. D., Dewulf, J., and Van Langenhove, H. (2011). Direct-injection mass spectrometry adds the time dimension to (B)VOC analysis. TrAC Trends Anal. Chem. 30, 1003-1017. doi: 10.1016/j.trac.2011.04.005

Bright, C. J., Nallon, E. C., Polcha, M. P., and Schnee, V. P. (2015). Quantum dot and polymer composite cross-reactive array for chemical vapor detection. Anal. Chem. 87, 12270-12275. doi: 10.1021/acs.analchem.5b03559

Brunner, C., Szymczak, W., Höllriegl, V., Mörtl, S., Oelmez, H., Bergner, A., et al. (2010). Discrimination of cancerous and non-cancerous cell lines by headspace-analysis with PTR-MS. Anal. Bioanal. Chem. 397, 2315-2324. doi: 10.1007/s00216-010-3838-x

Calderon-Santoyo, M., Bautista-Rosales, P. U., Luna-Solano, G., Ghommidh, C., and Ragazzo-Sanchez, J. A. (2013). Monitoring of lactic fermentation with a coupling electronic nose and gas chromatography. Engineering 5, 13-19. doi: 10.4236/eng.2013.59A002

Calderon-Santoyo, M., Chalier, P., Chevalier-Lucia, D., Ghommidh, C., and Ragazzo-Sanchez, J. A. (2010). Identification of Saccharomyces cerevisiae strains for alcoholic fermentation by discriminant factorial

analysis on electronic nose signals. Electron. J. Biotechnol. 13, 1-12. doi: 10.2225/vol13-issue4-fulltext-11

Carey, J. R., Suslick, K. S., Hulkower, K. I., Imlay, J. A., Imlay, K. R. C., Ingison, C. K., et al. (2011). Rapid identification of bacteria with a disposable colorimetric sensing array. J. Am. Chem. Soc. 133, 7571-7576. doi: 10.1021/ja201634d

Carrondo, M. J. T., Alves, P. M., Carinhas, N., Glassey, J., Hesse, F., Merten, O.W., et al. (2012). How can measurement, monitoring, modeling and control advance cell culture in industrial biotechnology? Biotechnol. J. 7, 1522-1529. doi: 10.1002/biot.201200226

Chen, J., Tang, J., Shi, H., Tang, C., and Zhang, R. (2017). Characteristics of volatile organic compounds produced from five pathogenic bacteria by headspacesolid phase micro-extraction/gas chromatography-mass spectrometry. J. Basic Microbiol. 57, 228-237. doi: 10.1002/jobm.201600505

Chen, Y., Banerjee, D., Mukhopadhyay, A., and Petzold, C. J. (2020). Systems and synthetic biology tools for advanced bioproduction hosts. Curr. Opin. Biotechnol. 4, 101-109. doi: 10.1016/j.copbio.2019.12.007

Chingin, K., Liang, J., and Chen, H. (2014). Direct analysis of in vitro grown microorganisms and mammalian cells by ambient mass spectrometry. RSC Adv. 4, 5768-5781. doi: 10.1039/c3ra46327c

Chippendale, T. W. E., Španěl, P., and Smith, D. (2011). Time-resolved selected ion flow tube mass spectrometric quantification of the volatile compounds generated by E. coli JM109 cultured in two different media. Rapid. Commun. Mass Spectrom. 25, 2163-2172. doi: 10.1002/rcm.5099

Chippendale, T. W. E., Spanel, P., Smith, D., and El Haj, A. J. (2014). Counting cell number in situ by quantification of dimethyl sulphide in culture headspace. Analyst 139, 4903-4907. doi: 10.1039/C4AN01102C

Chiu, S.-W., and Tang, K.-T. (2013). Towards a chemiresistive sensor-integrated electronic nose: a review. Sensors 13, 14214-14247. doi: 10.3390/s131014214

Cimander, C., Carlsson, M., and Mandenius, C.-F. (2002). Sensor fusion for on-line monitoring of yoghurt fermentation. J. Biotechnol. 99, 237-248. doi: 10.1016/S0168-1656(02)00213-4

Cimander, C., and Mandenius, C.-F. (2002). Online monitoring of a bioprocess based on a multi-analyser system and multivariate statistical process modelling. J. Chem. Technol. Biotechnol. 77, 1157-1168. doi: 10.1002/jctb.691

Clemente, J. J., Monteiro, S. M. S., Carrondo, M. J. T., and Cunha, A. E. (2008). Predicting sporulation events in a bioreactor using an electronic nose. Biotechnol. Bioeng. 101, 545-552. doi: 10.1002/bit.21920

Coutinho, D. M., França, D., Vanini, G., Mendes, L. A. N., Gomes, A. O., Pereira, V. B., et al. (2018). Rapid hydrocarbon group-type semi-quantification in crude oils by comprehensive two-dimensional gas chromatography. Fuel 220, 379-388. doi: 10.1016/j.fuel.2018.02.009

Cuenca, M., Ciesa, F., Romano, A., Robatscher, P., Scampicchio, M., and Biasioli, F. (2016). Mead fermentation monitoring by proton transfer reaction mass spectrometry and medium infrared probe. Eur. Food Res. Technol. 242, 1755-1762. doi: 10.1007/s00217-016-2675-3

Cuypers, W., and Lieberzeit, P. A. (2018). Combining two selection principles: sensor arrays based on both biomimetic recognition and chemometrics. Front. Chem. 6:268. doi: 10.3389/fchem.2018.00268

de Bournonville, S., Lambrechts, T., Vanhulst, J., Luyten, F. P., Papantoniou, I., and Geris, L. (2019). Towards self-regulated bioprocessing: a compact benchtop bioreactor system for monitored and controlled 3D cell and tissue culture. Biotechnol. J. 14:1800545. doi: 10.1002/biot.201800545

Dumont, J., Euwart, D., Mei, B., Estes, S., and Kshirsagar, R. (2016). Human cell lines for biopharmaceutical manufacturing: history, status, and future perspectives. Crit. Rev. Biotechnol. 36, 1110-1122. doi: 10.3109/07388551.2015.1084266

Faassen, S. M., and Hitzmann, B. (2015). Fluorescence spectroscopy and chemometric modeling for bioprocess monitoring. Sensors 15, 10271-10291. doi: $10.3390 / \mathrm{s} 150510271$ 
Fan, R., Ebrahimi, M., Quitmann, H., Aden, M., and Czermak, P. (2016). An innovative optical sensor for the online monitoring and control of biomass concentration in a membrane bioreactor system for lactic acid production. Sensors 16:411. doi: 10.3390/s16030411

Fernández-García, J., Altea-Manzano, P., Pranzini, E., and Fendt, S.-M. (2020). Stable isotopes for tracing mammalian-cell metabolism in vivo. Trends Biochem. Sci. 45, 185-201. doi: 10.1016/j.tibs.2019.12.002

Feuz, L., Jönsson, P., Jonsson, M. P., and Höök, F. (2010). Improving the limit of detection of nanoscale sensors by directed binding to high-sensitivity areas. ACS Nano 4, 2167-2177. doi: 10.1021/nn901457f

Filipiak, W., Sponring, A., Filipiak, A., Ager, C., Schubert, J., Miekisch, W., et al. (2010). TD-GC-MS analysis of volatile metabolites of human lung cancer and normal cells in vitro. Cancer Epidemiol. Biomark. Prev. 19, 182-195. doi: 10.1158/1055-9965.EPI-09-0162

Guarrasi, V., Sannino, C., Moschetti, M., Bonanno, A., Di Grigoli, A., and Settanni, L. (2017). The individual contribution of starter and nonstarter lactic acid bacteria to the volatile organic compound composition of caciocavallo palermitano cheese. Int. J. Food Microbiol. 259, 35-42. doi: 10.1016/j.ijfoodmicro.2017.07.022

Guidetti Vendruscolo, R., Bittencourt Fagundes, M., Jacob-Lopes, E., and Wagner, R. (2019). Analytical strategies for using gas chromatography to control and optimize microalgae bioprocessing. Curr. Opin. Food Sci. 25, 73-81. doi: $10.1016 /$ j.cofs.2019.02.008

Hansel, A., Jordan, A., Holzinger, R., Prazeller, P., Vogel, W., and Lindinger, W. (1995). Proton transfer reaction mass spectrometry: on-line trace gas analysis at the ppb level. Int. J. Mass Spectrom. Ion Proces. 149-150, 609-619. doi: 10.1016/0168-1176(95)04294-U

Henriques, J. G., Buziol, S., Stocker, E., Voogd, A., and Menezes, J. C. (2009). "Monitoring mammalian cell cultivations for monoclonal antibody production using near-infrared spectroscopy," in Optical Sensor Systems in Biotechnology, ed. G. Rao (Berlin: Springer), 29-72. doi: 10.1007/10_2009_11

Hillenkamp, F., Karas, M., Beavis, R. C., and Chait, B. T. (1991). Matrix-assisted laser desorption/ionization mass spectrometry of biopolymers. Anal. Chem. 63, 1193A-1203A. doi: 10.1021/ac00024a716

Hines, E. L., Llobet, E., and Gardner, J. W. (1999). Electronic noses: a review of signal processing techniques. IEE Proc. Circuits Devices Syst. 146, 297-310. doi: 10.1049/ip-cds:19990670

Holzberg, T. R., Watson, V., Brown, S., Andar, A., Ge, X., Kostov, Y., et al. (2018). Sensors for biomanufacturing process development: facilitating the shift from batch to continuous manufacturing. Curr. Opin. Chem. Eng. 22, 115-127. doi: 10.1016/j.coche.2018.09.008

$\mathrm{Hu}, \mathrm{Z}$., Deibert, B. J., and Li, J. (2014). Luminescent metal-organic frameworks for chemical sensing and explosive detection. Chem. Soc. Rev. 43, 5815-5840. doi: 10.1039/C4CS00010B

Huang, W., Diallo, A. K., Dailey, J. L., Besar, K., and Katz, H. E. (2015). Electrochemical processes and mechanistic aspects of field-effect sensors for biomolecules. J Mater. Chem. C 3, 6445-6470. doi: 10.1039/C5TC00755K

Jayawardane, B. M., McKelvie, I. D., and Kolev, S. D. (2015). Development of a gas-diffusion microfluidic paper-based analytical device ( $\mu$ PAD) for the determination of ammonia in wastewater samples. Anal. Chem. 87, 4621-4626. doi: 10.1021/acs.analchem.5b00125

Joo, S., and Brown, R. B. (2008). Chemical sensors with integrated electronics. Chem. Rev. 108, 638-651. doi: 10.1021/cr068113+

Kambayashi, T., Noguchi, T., Nojima, A., Kono, S., Taniguchi, S., and Ozaki, Y. (2020). Glucose monitoring in cell culture with online ultrasound-assisted near-infrared spectroscopy. Anal. Chem. 92, 2946-2952. doi: 10.1021/acs.analchem.9b03354

Kammies, T.-L., Manley, M., Gouws, P. A., and Williams, P. J. (2016). Differentiation of foodborne bacteria using NIR hyperspectral imaging and multivariate data analysis. Appl. Microbiol. Biotechnol. 100, 9305-9320. doi: 10.1007/s00253-016-7801-4

Kawano, Y., Shiroyama, M., Kanazawa, K., Suzuki, Y. A., and Ohtsu, I. (2019). Development of high-throughput quantitative analytical method for l-cysteinecontaining dipeptides by LC-MS/MS toward its fermentative production. AMB Express 9:91. doi: 10.1186/s13568-019-0817-2

Kiilerich-Pedersen, K., Poulsen, C. R., Jain, T., and Rozlosnik, N. (2011). Polymer based biosensor for rapid electrochemical detection of virus infection of human cells. Biosens. Bioelectron. 28, 386-392. doi: 10.1016/j.bios.2011.07.053
Komaraiah, P., Navratil, M., Carlsson, M., Jeffers, P., Brodelius, M., Brodelius, P. E., et al. (2004). Growth behavior in plant cell cultures based on emissions detected by a multisensor array. Biotechnol. Progr. 20, 1245-1250. doi: 10.1021/bp034231w

Konvalina, G., and Haick, H. (2014). Sensors for breath testing: from nanomaterials to comprehensive disease detection. Acc. Chem. Res. 47, 66-76. doi: $10.1021 /$ ar400070m

Kreij, K., Mandenius, C.-F., Clemente, J. J., Cunha, A. E., Monteiro, S. M. S., Carrondo, M. J. T., et al. (2005). On-line detection of microbial contaminations in animal cell reactor cultures using an electronic nose device. Cytotechnology 48, 41-58. doi: 10.1007/s10616-005-3587-4

La Nasa, J., Modugno, F., Colombini, M. P., and Degano, I. (2019). Validation study of selected ion flow tube-mass spectrometry (SIFT-MS) in heritage science: characterization of natural and synthetic paint varnishes by portable mass spectrometry. J. Am. Soc. Mass. Spectrom. 30, 2250-2258. doi: 10.1007/s13361-019-02305-4

Lalonde, M.-E., and Durocher, Y. (2017). Therapeutic glycoprotein production in mammalian cells. J. Biotechnol. 251, 128-140. doi: 10.1016/j.jbiotec.2017.04.028

Langejuergen, J., Wagner, C., Beutel, S., Hopmeier, T., Scheper, T., and Zimmermann, S. (2015). Non-invasive monitoring of bacterial growth and auto-induced protein production in a bioreactor with a closed-loop GC-IMS. Int. J. Ion Mobil. Spectr. 18, 9-15. doi: 10.1007/s12127-014-0163-7

Lavra, L., Catini, A., Ulivieri, A., Capuano, R., Baghernajad Salehi, L., Sciacchitano, S., et al. (2015). Investigation of VOCs associated with different characteristics of breast cancer cells. Sci. Rep. 5:13246. doi: 10.1038/srep13246

Lawal, O., Knobel, H., Weda, H., Bos, L. D., Nijsen, T. M. E., Goodacre, R., et al. (2018). Volatile organic compound signature from co-culture of lung epithelial cell line with Pseudomonas aeruginosa. Analyst 143, 3148-3155. doi: 10.1039/C8AN00759D

Li, M., Wijewardane, N. K., Ge, Y., Xu, Z., and Wilkins, M. R. (2020). Visible/near infrared spectroscopy and machine learning for predicting polyhydroxybutyrate production cultured on alkaline pretreated liquor from corn stover. Bioresour. Technol. Rep. 9:100386. doi: 10.1016/j.biteb.2020.100386

Li, S., and Shui, W. (2020). Systematic mapping of protein-metabolite interactions with mass spectrometry-based techniques. Curr. Opin. Biotechnol. 64, 24-31. doi: 10.1016/j.copbio.2019.09.002

Li, Z., Askim, J. R., and Suslick, K. S. (2019). The optoelectronic nose: colorimetric and fluorometric sensor arrays. Chem. Rev. 119, 231-292. doi: 10.1021/acs.chemrev.8b00226

Li, Z., Bassett, W. P., Askim, J. R., and Suslick, K. S. (2015). Differentiation among peroxide explosives with an optoelectronic nose. Chem. Commun. 51, 15312-15315. doi: 10.1039/C5CC06221G

Li, Z., and Suslick, K. S. (2018). Ultrasonic preparation of porous silicadye microspheres: sensors for quantification of urinary trimethylamine Noxide. ACS Appl. Mater. Interfaces 10, 15820-15828. doi: 10.1021/acsami.8b 00995

Li, Z., and Suslick, K. S. (2019). Colorimetric sensor array for monitoring CO and ethylene. Anal. Chem. 91, 797-802. doi: 10.1021/acs.analchem.8b 04321

Liden, H., Bachinger, T., Gorton, L., and Mandenius, C.-F. (2000). Online determination of non-volatile or low-concentration metabolites in a yeast cultivation using an electronic nose. Analyst 125, 1123-1128. doi: 10.1039/a909585c

López, M. E., Rene, E. R., Boger, Z., Veiga, M. C., and Kennes, C. (2017). Modelling the removal of volatile pollutants under transient conditions in a two-stage bioreactor using artificial neural networks. J. Hazard. Mater. 324, 100-109. doi: 10.1016/j.jhazmat.2016.03.018

Lourenço, N. D., Lopes, J. A., Almeida, C. F., Sarraguça, M. C., and Pinheiro, H. M. (2012). Bioreactor monitoring with spectroscopy and chemometrics: a review. Anal. Bioanal. Chem. 404, 1211-1237. doi: 10.1007/s00216-012-6073-9

Luchner, M., Gutmann, R., Bayer, K., Dunkl, J., Hansel, A., Herbig, J., et al. (2012). Implementation of proton transfer reaction-mass spectrometry (PTRMS) for advanced bioprocess monitoring. Biotechnol. Bioeng. 109, 3059-3069. doi: 10.1002/bit.24579

MacMullan, M. A., Dunn, Z. S., Graham, N., Yang, L., and Wang, P. (2019). Quantitative proteomics and metabolomics reveal biomarkers of disease as potential immunotherapy targets and indicators of therapeutic efficacy. Theranostics 9, 7872-7888. doi: 10.7150/thno.37373 
Mandenius, C.-F. (2000). "Electronic noses for bioreactor monitoring," in Bioanalysis and Biosensors for Bioprocess Monitoring. ed. B. Sonnleitner (Berlin: Springer Berlin Heidelberg), 65-82. doi: 10.1007/3-540-487 73-5_2

Matthews, T. E., Berry, B. N., Smelko, J., Moretto, J., Moore, B., and Wiltberger, K. (2016). Closed loop control of lactate concentration in mammalian cell culture by raman spectroscopy leads to improved cell density, viability, and biopharmaceutical protein production. Biotechnol. Bioeng. 113, 2416-2424. doi: 10.1002/bit.26018

Maynor, M. S., Nelson, T. L., O'Sulliva, C., and Lavigne, J. J. (2007). A food freshness sensor using the multistate response from analyte-induced aggregation of a cross-reactive poly(thiophene). Org. Lett. 9, 3217-3220. doi: $10.1021 /$ ol071065a

McCartney, M. M., Yamaguchi, M. S., Bowles, P. A., Gratch, Y. S., Iyer, R. K., Linderholm, A. L., et al. (2019). Volatile organic compound (VOC) emissions of $\mathrm{CHO}$ and $\mathrm{T}$ cells correlate to their expansion in bioreactors. J Breath Res. 14:016002. doi: 10.1088/1752-7163/ab3d23

McConnell, B. O., and Antoniewicz, M. R. (2016). Measuring the composition and stable-isotope labeling of algal biomass carbohydrates via gas chromatography/mass spectrometry. Anal. Chem. 88, 4624-4628. doi: 10.1021 /acs.analchem.6b00779

Mcnair, H., and Miller, J. M. (2010). Basic Gas Chromatography. Hoboken, NJ: John Wiley \& Sons, Inc. doi: 10.5860/CHOICE.47-5660

Meunier, S. M., Todorovic, B., Dare, E. V., Begum, A., Guillemette, S., Wenger, A., et al. (2016). Impact of dissolved oxygen during uv-irradiation on the chemical composition and function of CHO cell culture media. PLoS ONE 11:e0150957. doi: 10.1371/journal.pone.0150957

Michl, J., Park, K. C., and Swietach, P. (2019). Evidence-based guidelines for controlling pH in mammalian live-cell culture systems. Commun. Biol. 2:144. doi: 10.1038/s42003-019-0393-7

Nakamoto, T., and Ishida, H. (2008). Chemical sensing in spatial/temporal domains. Chem. Rev. 108, 680-704. doi: 10.1021/cr068117e

Namdev, P. K., Alroy, Y., and Singh, V. (1998). Sniffing out trouble: use of an electronic nose in bioprocesses. Biotechnol. Progr. 14, 75-78. doi: 10.1021/bp970141d

Narsaiah, K., Jha, S. N., Bhardwaj, R., Sharma, R., and Kumar, R. (2012). Optical biosensors for food quality and safety assurance-a review. J. Food Sci. Technol. 49, 383-406. doi: 10.1007/s13197-011-0437-6

Nespeca, M. G., Rodrigues, C. V., Santana, K. O., Maintinguer, S. I., and de Oliveira, J. E. (2017). Determination of alcohols and volatile organic acids in anaerobic bioreactors for $\mathrm{H} 2$ production by near infrared spectroscopy. Int. J. Hydrog. Energy 42, 20480-20493. doi: 10.1016/j.ijhydene.2017.07.044

Nielsen, J., and Keasling, J. D. (2016). Engineering cellular metabolism. Cell 164, 1185-1197. doi: 10.1016/j.cell.2016.02.004

Noui, L., Hill, J., Keay, P. J., Wang, R. Y., Smith, T., Yeung, K., et al. (2002). Development of a high resolution UV spectrophotometer for at-line monitoring of bioprocesses. Chem. Eng. Process. Process Intensif. 41, 107-114. doi: 10.1016/S0255-2701(01)00122-2

Oyetunde, T., Bao, F. S., Chen, J.-W., Martin, H. G., and Tang, Y. J. (2018). Leveraging knowledge engineering and machine learning for microbial bio-manufacturing. Biotechnol. Adv. 36, 1308-1315. doi: 10.1016/j.biotechadv.2018.04.008

Pais, D. A. M., Carrondo, M. J. T., Alves, P. M., and Teixeira, A. P. (2014). Towards real-time monitoring of therapeutic protein quality in mammalian cell processes. Curr. Opin. Biotechnol. 30, 161-167. doi: 10.1016/j.copbio.2014.06.019

Pan, D. D., Wu, Z., Peng, T., Zeng, X. Q., and Li, H. (2014). Volatile organic compounds profile during milk fermentation by Lactobacillus pentosus and correlations between volatiles flavor and carbohydrate metabolism. J. Dairy Sci. 97, 624-631. doi: 10.3168/jds.2013-7131

Parente, E., Piraino, P., Fidaleo, M., and Moresi, M. (2004). Overall volumetric oxygen transfer coefficient in an aerated bench-top stirred fermenter in aqueous dispersions of sodium alginate. Biotechnol. Appl. Biochem. 40, 133-143. doi: 10.1042/BA20030213

Persaud, K., and Dodd, G. (1982). Analysis of discrimination mechanisms in the mammalian olfactory system using a model nose. Nature 299, 352-355. doi: $10.1038 / 299352 \mathrm{a} 0$
Plusquellic, D. F., Siegrist, K., Heilweil, E. J., and Esenturk, O. (2007). Applications of terahertz spectroscopy in biosystems. ChemPhysChem 8, 2412-2431. doi: $10.1002 / \mathrm{cphc} .200700332$

Pontius, K., Praticò, G., Larsen, F. H., Skov, T., Arneborg, N., Lantz, A. E., et al. (2020). Fast measurement of phosphates and ammonium in fermentation-like media: a feasibility study. N. Biotechnol. 56, 54-62. doi: 10.1016/j.nbt.2019.11.006

Rakow, N. A., and Suslick, K. S. (2000). A colorimetric sensor array for odour visualization. Nature 406, 710-713. doi: 10.1038/35021028

Riahi, R., Shaegh, S. A. M., Ghaderi, M., Zhang, Y. S., Shin, S. R., Aleman, J., et al. (2016). Automated microfluidic platform of bead-based electrochemical immunosensor integrated with bioreactor for continual monitoring of cell secreted biomarkers. Sci. Rep. 6:24598. doi: 10.1038/srep24598

Roch, P., and Mandenius, C.-F. (2016). On-line monitoring of downstream bioprocesses. Curr. Opin. Chem. Eng. 14, 112-120. doi: 10.1016/j.coche.2016.09.007

Rocha-Gaso, M.-I., March-Iborra, C., Montoya-Baides, Á., and Arnau-Vives, A. (2009). Surface generated acoustic wave biosensors for the detection of pathogens: a review. Sensors 9, 5740-5769. doi: 10.3390/s9095740

Rock, F., Barsan, N., and Weimar, U. (2008). Electronic nose: current status and future trends. Chem. Rev. 108, 705-725. doi: 10.1021/cr068121q

Romano, A., Capozzi, V., Spano, G., and Biasioli, F. (2015). Proton transfer reaction-mass spectrometry: online and rapid determination of volatile organic compounds of microbial origin. Appl. Microbiol. Biotechnol. 99, 3787-3795. doi: 10.1007/s00253-015-6528-y

Rosi, P. E., Miscoria, S. A., Bernik, D. L., and Martín Negri, R. (2012). Customized design of electronic noses placed on top of air-lift bioreactors for in situ monitoring the off-gas patterns. Bioprocess and Biosyst. Eng. 35, 835-842. doi: 10.1007/s00449-011-0667-z

Rowland-Jones, R. C., van den Berg, F., Racher, A. J., Martin, E. B., and Jaques, C. (2017). Comparison of spectroscopy technologies for improved monitoring of cell culture processes in miniature bioreactors. Biotechnol. Progr. 33, 337-346. doi: 10.1002/btpr.2459

Roychoudhury, P., O’Kennedy, R., McNeil, B., and Harvey, L. M. (2007). Multiplexing fibre optic near infrared (NIR) spectroscopy as an emerging technology to monitor industrial bioprocesses. Anal. Chim. Acta 590, 110-117. doi: 10.1016/j.aca.2007.03.011

Santos, R. M., Kessler, J. M., Salou, P., Menezes, J. C., and Peinado, A. (2018). Monitoring $\mathrm{mAb}$ cultivations with in-situ raman spectroscopy: the influence of spectral selectivity on calibration models and industrial use as reliable PAT tool. Biotechnol. Progr. 34, 659-670. doi: 10.1002/btpr.2635

Schaude, C., Meindl, C., Fröhlich, E., Attard, J., and Mohr, G. J. (2017). Developing a sensor layer for the optical detection of amines during food spoilage. Talanta 170, 481-487. doi: 10.1016/j.talanta.2017.04.029

Schmidberger, T., Gutmann, R., Bayer, K., Kronthaler, J., and Huber, R. (2014). Advanced online monitoring of cell culture off-gas using proton transfer reaction mass spectrometry. Biotechnol. Progr. 30, 496-504. doi: $10.1002 /$ btpr. 1853

Schmidberger, T., and Huber, R. (2013). Advanced off-gas measurement using proton transfer reaction mass spectrometry to predict cell culture parameters. BMC Proc. 7:P14. doi: 10.1186/1753-6561-7-S6-P14

Schmidt, S., Kircher, M., Kasala, J., and Locaj, J. (1998). Near infrared spectroscopy in fermentation and quality control for amino acid production. Bioprocess. Eng. 19, 67-70. doi: 10.1007/s004490050484

Schoen, H. R., Peyton, B. M., and Knighton, W. B. (2016). Rapid total volatile organic carbon quantification from microbial fermentation using a platinum catalyst and proton transfer reaction-mass spectrometry. AMB Express 6:90. doi: 10.1186/s13568-016-0264-2

Shaw, A. D., Kaderbhai, N., Jones, A., Woodward, A. M., Goodacre, R., Rowland, J. J., et al. (1999). Noninvasive, on-line monitoring of the biotransformation by yeast of glucose to ethanol using dispersive raman spectroscopy and chemometrics. Appl. Spectrosc. 53, 1419-1428. doi: 10.1366/0003702991945777

Shen, Z., Huang, M., Xiao, C., Zhang, Y., Zeng, X., and Wang, P. G. (2007). Nonlabeled QCM biosensor for bacterial detection using carbohydrate and lectin recognitions. Anal. Chem. 79, 2312-2319. doi: 10.1021/ac061986j

Silva, G. O., Michael, Z. P., Bian, L., Shurin, G. V., Mulato, M., Shurin, M. R., et al. (2017). Nanoelectronic discrimination of non-malignant and 
malignant cells using nanotube field-effect transistors. ACS Sens. 2, 1128-1132. doi: 10.1021/acssensors.7b00383

Soukoulis, C., Aprea, E., Biasioli, F., Cappellin, L., Schuhfried, E., Mark, T. D., et al. (2010). Proton transfer reaction time-of-flight mass spectrometry monitoring of the evolution of volatile compounds during lactic acid fermentation of milk. Rapid. Commun. Mass Spectrom. 24, 2127-3134. doi: 10.1002/rcm.4617

Su, S., Wu, W., Gao, J., Lu, J., and Fan, C. (2012). Nanomaterials-based sensors for applications in environmental monitoring. J. Mater. Chem. 22, 18101-18110. doi: $10.1039 / \mathrm{c} 2 \mathrm{jm} 33284 \mathrm{a}$

Tang, H., Lu, Y., Zhang, L., Wu, Z., Hou, X., and Xia, H. (2017). Determination of volatile organic compounds exhaled by cell lines derived from hematological malignancies. Biosci. Rep. 37:BSR20170106. doi: 10.1042/BSR20170106

Teixeira, A. P., Oliveira, R., Alves, P. M., and Carrondo, M. J. T. (2009). Advances in on-line monitoring and control of mammalian cell cultures: supporting the PAT initiative. Biotechnol. Adv. 27, 726-732. doi: 10.1016/j.biotechadv.2009.05.003

Tomita, S., Niwa, O., and Kurita, R. (2016). Artificial modification of an enzyme for construction of cross-reactive polyion complexes to fingerprint signatures of proteins and mammalian cells. Anal. Chem. 88, 9079-9086. doi: 10.1021/acs.analchem.6b02010

Tulsyan, A., Wang, T., Schorner, G., Khodabandehlou, H., Coufal, M., and Undey, C. (2019). Automatic real-time calibration, assessment, and maintenance of generic raman models for online monitoring of cell culture processes. Biotechnol. Bioeng. 117, 406-416. doi: 10.1002/bit.27205

Ulrike, T., and Hossam, H. (2014). Chemical sensors for breath gas analysis: the latest developments at the breath analysis summit 2013. J Breath Res. 8:027103. doi: 10.1088/1752-7155/8/2/027103

Valente, K. N., Levy, N. E., Lee, K. H., and Lenhoff, A. M. (2018). Applications of proteomic methods for $\mathrm{CHO}$ host cell protein characterization in biopharmaceutical manufacturing. Curr. Opin. Biotechnol. 53, 144-150. doi: 10.1016/j.copbio.2018.01.004

Van Kerrebroeck, S., Vercammen, J., Wuyts, R., and De Vuyst, L. (2015). Selected ion flow tube-mass spectrometry for online monitoring of submerged fermentations: a case study of sourdough fermentation. J. Agric. Food. Chem. 63, 829-835. doi: 10.1021/jf505111m

Viola, R., Mengali, S., Libetatore, N., Zampolli, S., Elmi, I., and Mancarella, F. (2019). "Deployable sensor for trace identification of hazardous chemicals in dirty environment, based on FAST gas-chromatography and quartz enhanced photoacoustic spectroscopy," in 2019 PhotonIcs \& Electromagnetics Research Symposium - Spring (PIERS-Spring) (Rome: IEEE), 223-228. doi: 10.1109/PIERS-Spring46901.2019.9017698

Wang, J., Zhang, H. Z., Li, R. S., and Huang, C. Z. (2016). Localized surface plasmon resonance of gold nanorods and assemblies in the view of biomedical analysis. TrAC Trends Anal. Chem. 80, 429-443. doi: 10.1016/j.trac.2016.03.015

Wang, Y., Fan, L., Tuyishime, P., Zheng, P., and Sun, J. (2020). Synthetic methylotrophy: a practical solution for methanol-based biomanufacturing. Trends Biotechnol. 38, 650-666. doi: 10.1016/j.tibtech.2019.12.013
Wang, Y., Hu, Y., Wang, D., Yu, K., Wang, L., Zou, Y., et al. (2012). The analysis of volatile organic compounds biomarkers for lung cancer in exhaled breath, tissues and cell lines. Cancer Biomark. 11, 129-137. doi: 10.3233/CBM-2012-00270

Wei, Q., Nagi, R., Sadeghi, K., Feng, S., Yan, E., Ki, S. J., et al. (2014). Detection and spatial mapping of mercury contamination in water samples using a smart-phone. ACS Nano 8, 1121-1129. doi: 10.1021/nn406571t

Wu, J., Kwon, B., Liu, W., Anslyn, E. V., Wang, P., and Kim, J. S. (2015). Chromogenic/fluorogenic ensemble chemosensing systems. Chem. Rev. 115, 7893-7943. doi: 10.1021/cr500553d

Young, A. T., Rivera, K. R., Erb, P. D., and Daniele, M. A. (2019). Monitoring of microphysiological systems: integrating sensors and real-time data analysis toward autonomous decision-making. ACS Sens. 4, 1454-1464. doi: 10.1021/acssensors.8b01549

Yu, Z., Huang, H., Reim, A., Charles, P. D., Northage, A., Jackson, D., et al. (2017). Optimizing 2D gas chromatography mass spectrometry for robust tissue, serum and urine metabolite profiling. Talanta 165, 685-691. doi: 10.1016/j.talanta.2017.01.003

Zavala-Ortiz, D. A., Ebel, B., Li, M.-Y., Barradas-Dermitz, D. M., HaywardJones, P. M., Aguilar-Uscanga, M. G., et al. (2020). Interest of locally weighted regression to overcome non-linear effects during in situ NIR monitoring of CHO cell culture parameters and antibody glycosylation. Biotechnol. Progr. 36:e2924. doi: 10.1002/btpr.2924

Zhang, M.-L., Sheng, G.-P., Mu, Y., Li, W.-H., Yu, H.-Q., Harada, H., et al. (2009). Rapid and accurate determination of VFAs and ethanol in the effluent of an anaerobic H2-producing bioreactor using near-infrared spectroscopy. Water Res. 43, 1823-1830. doi: 10.1016/j.watres.2009.01.018

Zhang, W. G., Chu, X. G., Cai, H. X., An, J., and Li, C. J. (2006). Simultaneous determination of 109 pesticides in unpolished rice by a combination of gel permeation chromatography and florisil column purification, and gas chromatography/mass spectrometry. Rapid Commun. Mass Spectrom. 20, 609-617. doi: $10.1002 / \mathrm{rcm} .2341$

Zhao, L., Fu, H.-Y., Zhou, W., and Hu, W.-S. (2015). Advances in process monitoring tools for cell culture bioprocesses. Eng. Life Sci. 15, 459-468. doi: 10.1002/elsc.201500006

Conflict of Interest: The authors declare that the research was conducted in the absence of any commercial or financial relationships that could be construed as a potential conflict of interest.

Copyright (C) 2020 Chen, Hu, Hu, Huang, Shi, Wei and Li. This is an open-access article distributed under the terms of the Creative Commons Attribution License (CC $B Y)$. The use, distribution or reproduction in other forums is permitted, provided the original author(s) and the copyright owner(s) are credited and that the original publication in this journal is cited, in accordance with accepted academic practice. No use, distribution or reproduction is permitted which does not comply with these terms. 